\title{
Presumed Ocular Toxoplasmosis In University Of Uyo Teaching Hospital, Uyo, Nigeria
}

\author{
Abraham, Emem G. ${ }^{1,}$ Umanah, Ivy N. ${ }^{2,}$ Uwah, Akaninyene I. ${ }^{3,}$ Edet, Enoima ${ }^{3}$ \\ ${ }^{1,3}$ Departments of Ophthalmology, and ${ }^{2}$ Pathology, University of Uyo Teaching Hospital (UUTH), P.M.B. 1136, \\ Uyo, Akwa Ibom State, Nigeria.
}

\begin{abstract}
Background:Ocular toxoplasmosis is the commonest cause of infectious posterior uveitis the world over. Ocular symptoms may present years after the systemic infection and the outcome depends on the interaction of many factors. The objective of this study was to assess the prevalence of presumed ocular toxoplasmosis amongst patients attending the eye clinic of a tertiary hospital.

Materials and Methods:This was a retrospective study of 30 patients seen in the eye clinic of University of Uyo Teaching Hospital between January 2009 and December 2011. Demographic information, presenting and final visual acuity, presenting complaints, ocular findings and drug treatment were extracted from the clinical notes, and the data obtained was analyzed.

Results: A total of $30(0.28 \%)$ patients out of 10,595consecutive patients seen in the UUTH eye clinic. More women were affected (56.7\%) than men (43.3\%). The most affected age group was (41-50) years. The commonest complaint was diminution of vision. Final visual acuity was closely related to the site of the lesion on the retina.

Conclusion: The prevalence of ocular toxoplasmosis (0.28\%) was lower than that observed in other parts of the country. There is need to investigate the seroprevalence of toxoplasmosis in the general population, particularly in those at risk.
\end{abstract}

Key words: infections ocular, prevalence, toxoplasmosis,

\section{Introduction}

Toxoplasmosis is endemic in tropical Africa and South America. In these regions, infection with T gondii is mostly poverty related, where a population depending on surface water and fresh meat are at a particular high risk ${ }^{1}$. Studies have shown that most infections in Africa are acquired through contaminated food or water ${ }^{1,2}$

Ocular toxoplasmosis is the commonest cause of infectious posterior uveitis in the nonimmunocompromised individuals and second only to cytomegalovirus retinitis in patients with HIV/AIDS. ${ }^{3}$ Infection can be congenital or acquired. Ocular symptoms may present years after the systemic infection and systemic infection often go unnoticed in immunocompetent persons. Outcome of toxoplasmosis depends on the interaction of many factors including the function of the immune system and parasitic factor such as inoculums, infective parasitic stage and the genotype of $\mathrm{T}$. gondii.

\section{Aims And Objectives}

To assess the prevalence of presumed ocular toxoplasmosis amongst patients attending a tertiary eye clinic.

\section{Materials And Methods}

The records of all patients seen between January 2009 and December 2011 were reviewed and those who were clinically diagnosed with presumed ocular toxoplasmosis were included in the study. Their demographic information, the presenting and final visual acuity, presenting complaints, ocular findings and drug treatment were extracted from the case notes. Data was managed with SPSS17 statistical package.

\section{Result}

A total of 10,595 patients were seen between January 2009 and December 2011. Thirty $(0.28 \%)$ of this had signs and symptoms of presumed ocular toxoplasmosis. Thirty three cards were actually retrieved but three were excluded because of incomplete information. Of the thirty (30) patients in our study, 13 (43.3\%) were males while $17(56.7 \%)$ were females. The age range was between 9years to 82 years with a mean age of 41.47years.Table 1 shows the age distribution of patients with presumed ocular toxoplasmosis in UUTH, Uyo.The age group 41-50years had the greatest number of patients 8, followed by group 31-40 years which had 7 patients. The least number was seen in the extremes of life $(<20,>60)$.Diminution of vision was the chief complaints for 23(74.2\%) patients, while floaters with flashes of light with or without diminution of vision was 
the chief complaints in $6(19.3 \%)$.One patient $(3.2 \%)$ had anterior segment signs. Twelve patients $(38.7 \%)$ had hazy media with one patient bilateral. Ten patients (32.2\%) had vitreous floaters with one patient affected in both eyes. Of the 30 patients, 19(63.3\%) had active lesion, of these 2 were bilateral. Fifteen (50\%) had lesion located at the macular, $8(26.7 \%)$ on the major vessels, one peripapillary, four had multiple lesion, 7 in the periphery and 7patients had lesions in both eyes,. Two patients had haemorrhages in the background, 4 patients had other coexisting retinopathies. Sixteen $(53.3 \%)$ were placed on Daraprim/Septrin, 4patients $(13.3 \%)$ on Daraprim/Septrin/Prednisolone,one on Azithromycin /Septrin, others were treated for various other presenting complaints. Seven patients (23.3\%) showed improvement with improved VA, 7(23.3\%) improved with clearing of inflammation, flattening of lesion but no improvement on VA. For $2(6.6 \%)$ vision got worse due to coexisting cataract. Only 13 patients carried out the HIVscreening test which was requested for. Three(10\%) of these were HIV positive,10(33.3\%) were negative, and for 17(56.7\%) no test done.

TABLE 1: Age distribution of patients with presumed ocular toxoplasmosis in UUTH, Uyo

\begin{tabular}{|l|l|l|}
\hline Age (Years) & Number (n) & Percent (\%) \\
\hline $1-10$ & 1 & 3.3 \\
\hline $11-20$ & 1 & 3.3 \\
\hline $21-30$ & 6 & 20.0 \\
\hline $31-40$ & 7 & 23.3 \\
\hline $41-50$ & 8 & 26.7 \\
\hline $51-60$ & 5 & 16.7 \\
\hline $61-70$ & 1 & 3.3 \\
\hline$>70$ & 1 & 3.3 \\
\hline Total & $\mathbf{3 0}$ & $\mathbf{1 0 0}$ \\
\hline
\end{tabular}

TABLE 2: Chief complaints of patients with presumed ocular toxoplasmosis in UUTH, Uyo

\begin{tabular}{|l|l|l|}
\hline Complaints & Number (n) & Percent (\%) \\
\hline Dov only & 23 & 74.2 \\
\hline Dov/floaters & 5 & 16.1 \\
\hline Flashes of light/floaters & 1 & 3.3 \\
\hline Other complaints & 2 & 6.5 \\
\hline Total & $\mathbf{3 0}$ & $\mathbf{1 0 0 . 0}$ \\
\hline
\end{tabular}

${ }^{\dagger} \mathrm{DOV}=$ Diminution of vision

TABLE 3: Changes in the ocular media amongst patients with presumed ocular toxoplasmosis in UUTH, Uyo

\begin{tabular}{|c|c|c|c|c|c|c|c|c|}
\hline \multirow{3}{*}{$\begin{array}{l}\text { Changes in } \\
\text { media }\end{array}$} & \multicolumn{4}{|c|}{ Yes } & \multicolumn{2}{|l|}{ No } & \multicolumn{2}{|c|}{ Total } \\
\hline & \multicolumn{2}{|c|}{ one eye } & \multicolumn{2}{|c|}{ Both eyes } & & & & \\
\hline & $\mathbf{n}$ & $\%$ & $\mathbf{n}$ & $\%$ & $\mathbf{n}$ & $\%$ & $\mathbf{N}$ & $\%$ \\
\hline Hazy media & 11.0 & 36.7 & 1.0 & 3.3 & 18.0 & 60.0 & 30.0 & 100.0 \\
\hline Vitreous cells & 9.0 & 30.0 & 1.0 & 3.3 & 20.0 & 66.7 & 30.0 & 100.0 \\
\hline
\end{tabular}

TABLE 4: Location of lesion in patients with presumed ocular toxoplasmosis in UUTH, Uyo

\begin{tabular}{|l|c|c|}
\hline Location of lesion & Number(n) & Percentage(\%) \\
\hline Posterior pole & 15 & 48.4 \\
\hline Involving vessels & 8 & 25.8 \\
\hline Peripappilary & 1 & 3.2 \\
\hline Periphery & 7 & 22.6 \\
\hline
\end{tabular}

TABLE 5: Drugs used in patients with presumed ocular toxoplasmosis in UUTH, Uyo

\begin{tabular}{|l|l|l|}
\hline Drug & Number $(\mathbf{n})$ & Percent $(\%)$ \\
\hline Daraprim/septrin & 16 & 53.3 \\
\hline Daraprim/septrin/prednisolone & 4 & 13.3 \\
\hline Azithromycin & 1 & 3.3 \\
\hline Treated for other conditions & 9 & 30.1 \\
\hline Total & $\mathbf{3 0}$ & $\mathbf{1 0 0}$ \\
\hline
\end{tabular}




\section{Discussion}

Of the 10595 people who attended the eye clinic, 33 were seen with presumed ocular toxoplasmosis 3 cards had incomplete records and so were not included. Analysis was based on the records of 30 patients giving a prevalence of $0.28 \%$

Out of the 30 patients, $13(43.3 \%)$ were males while $17(56.7 \%)$ were female. This is in contrast to other studies for seroprevalence of IgG antibody titre for T. gondii in Maiduguri, Northern Nigeria by Kamari, where males formed $27.3 \%$ and females $19.8 \%{ }^{4}$. Uneke ${ }^{5}$ in Jos-Northern, Nigeria also had seroprevalence of males $22.0 \%$, females $20.0 \%$. This may be because the males are those involved in cattle rearing and abattoir work in Northern Nigeria. A study in Iran by Kianersi ${ }^{6}$ had $57.5 \%$ females and $42.5 \%$ males.

The age range was between 9-82years with a mean of 41.47years. The most affected age group was 41 $50 y e a r s(8)$ followed by $31-40(7)$. The least affected group was in the extremes of life $(<20 \&>60)$. This is similar to the findings in Maiduguri ${ }^{3}$ where the age group with highest seroprevalence was 51-60years least affected were those $<21$ yrs.

In 23 of our patients (74.2\%) presenting complaints was diminution of vision only, while $5(14.3 \%)$ presenting complaint was floaters and flashes of light with or without diminution of vision. This is consistent with the study in Iran by Kianersi ${ }^{6}$ where $96 \%$ of patients complained of diminution of vision and $13.47 \%$ of floaters. Ten of our patients (33.5\%) had signs and symptoms of vitritis, $2(6.5 \%)$ anterior uveitis. This is consistent with the findings in Serbia by Koracevic'-Paricevic ${ }^{-7,8}$. Signs and symptoms of anterior uveitis may coexist in patient with posterior uveitis secondary to ocular toxoplasmosis.

Eighty three percent $(83.3 \%)$ of the lesion was uniocular and $16.7 \%$ binocular as seen in many other studies 6,7 . Most of the lesion $15(48.4 \%)$ affected the posterior pole as seen in other studies ${ }^{7,9}$. Some cases of atypical presentation were also seen in patients who were HIV positive as noted in other studies. ${ }^{8,10}$

The presenting visual acuity (VA) was between 6/36-HM, while the VA at last visit ranged between $6 / 12$ and counting finger (CF). Of those treated, $23.3 \%$ had improved VA, $23.3 \%$ had only clearing of the intraocular inflammation activity and flattening of the retinal lesion but no improvement in visual activity. This is consistent with other studies which have shown that outcome of treatment and final visual impairment were associated with the localization of the lesion and the degree of imflammation ${ }^{7,11}$

Follow up of these patients was very poor as only 13 came for repeat visit and 4 came for second follow up visit. The rest were lost to follow up.

\section{Conclusion And Recommendation}

We report our findings in 30 patients with presumed ocular toxoplasmosis. The prevalence was $0.28 \%$. The visual outcome depended largely on the location of the lesion

Though the prevalence of ocular toxoplasmosis appears low in this study, the visual outcome of the affected individuals is very significant and so the need to do seroprevalence study and take steps to reduce the endemicity of toxoplasmosis in our environment.

\section{References}

[1] Bahia-oliveira LM, Jones JL, Azevedo-Silva J etal. Highly endemic waterborne toxoplasmosis in north Rio de Janeiro state, Brasil Emerg Infect Dis 9,55-62(2003)

[2] Cork AJ,Gilbert RE, Buffolano et al: Sources of toxoplasma Infection in pregnant women: European multicentre case control study. Br Med J 2000; 321:142-147

[3] Soheilian M, Ramezani A, Soheilan R. How to diagnose and treat ocular Toxoplasmosis. Rev of ophthalmol12 (32) 2012

[4] Kameni J, Mani AU, Egwu GO et al. Seroprevalence of human infection with Toxoplasm gondii and the associated risk factors in Maiduguri, Borno State, Nigeria. Ann Trop Med Parasitol. 2009;103:317-321

[5] Uneke CJ,Duhlinska DD, Njoku MO, Ngwu BA: Seroprevalence of acquired toxolasmosis in HIV-infected and apparently healthy individuals in Jos, Nigeria. Parssitilogia 2005,47:233-236

[6] Kianersi F, Naderi Beni A, Naderi Beni Z. Clinical manifestation and prognosis of active ocular toxoplasmosis in Iran. Int. ophthalmol 2012 June 26

[7] Korac`evic'-Pavic`evic` D, Redosavljevic` A, Ilic`Korac`evic'I and Djurkovic-Djakovic': Clinical pattern of ocular toxoplasmosis treated in a referral centrenin Serbia. Eye(Lord) 2012 May;20(5): 723-8:doi:10.1038

[8] Alvarez G, Ray A, Ade`n A.Clinical features of ocular toxoplasmosis in immigrant population in the Barcelona area: study of 22 patients. Arch Soc Esp ofthalmol 2010;85(6):202-8

[9] Peterson E, Kiljstr A, Stanford M: Epidemiology of ocular Toxoplasmosis Ocul of Immunol Inflamm 2012;20(2):68-75

[10] Smith JR, Cunningham ETJr. Atypical presentation of ocular toxoplasmosis. Curr OpinOphthalmol 2002;13(6):387-92

[11] London NJ, Hovakimyan A, Cubillan LD et al. Prevalence, clinical characteristics, and causes of vision loss in patients with ocular toxoplasmosis. Eur J Ophthalmol. 2011;21:811-819. 